\title{
BMJ Open Do adult health outcomes in urban population reflect local health risk? A matched cohort analysis of migration effects in Ouagadougou, Burkina Faso
}

\author{
Philippe Bocquier, ${ }^{\oplus 1,2}$ Abdramane Bassiahi Soura, ${ }^{3}$ Souleymane Sanogo, ${ }^{3}$ \\ Sara Randall ${ }^{4}$
}

To cite: Bocquier $P$, Soura $A B$, Sanogo $S$, et al. Do adult health outcomes in urban population reflect local health risk? A matched cohort analysis of migration effects in Ouagadougou, Burkina Faso. BMJ Open 2019;9:e029059. doi:10.1136/ bmjopen-2019-029059

- Prepublication history and additional material for this paper are available online. To view these files, please visit the journal online (http://dx.doi org/10.1136/bmjopen-2019029059).

Received 28 February 2019 Revised 27 May 2019 Accepted 6 June 2019

Check for updates

(C) Author(s) (or their employer(s)) 2019. Re-use permitted under CC BY-NC. No commercial re-use. See rights and permissions. Published by BMJ.

${ }^{1}$ Centre de recherche en démographie, Université catholique de Louvain, Louvainla-Neuve, Belgium

${ }^{2}$ School of Public Health, University of the Witwatersrand, Johannesburg, Republic of

South Africa

${ }^{3}$ Institut supérieur des sciences de la population, Université de Ouagadougou, Ouagadougou, Burkina Faso

${ }^{4}$ Department of Anthropology, University College of London, London, UK

Correspondence to

Prof Philippe Bocquier;

philippe.bocquier@uclouvain.be

\section{ABSTRACT}

Background Selective migration may affect health indicators in both urban and rural areas. Sub-Saharan African urban areas show evidence of both negative and positive selection on health status at outmigration. Health outcomes as measured in urban populations may not reflect local health risks and access to health services. Methods Using the Ouagadougou Health and Demographic Surveillance System and a migrant followup survey, we measured differences in health between matched non-migrants and outmigrants. We applied Cox and competing risks models on migration and death. Results Controlling for premigration health status, migrants who moved out of Ouagadougou have higher mortality (HR 3.24, 95\% Cl 1.23 to 8.58) than non-migrants and migrants moving to other Ouagadougou areas. However, these effects vanish in the matched sample controlling for all interactions between death determinants. These and other results show little evidence that migration led to higher mortality or worse health.

Conclusions Health outcomes as measured in Ouagadougou population do reflect local health risks and access to health services despite high migration intensity. However, neither the hypothesis of effect of health on migration nor the hypothesis of negative effect of migration on health or survival was confirmed.

\section{BACKGROUND}

Selective migration may impact health indicators in both urban and rural areas. Migrants may be selected on health, leading to the 'healthy migrant' effect often attributed to new migrants, or on the contrary to 'unhealthy migrant' effect often attributed to return migrants. ${ }^{1}$ Such selection could lead to an urban health advantage if the healthy migrate in and unhealthy migrate out. Comparison between urban and rural sites in Burkina Faso showed positive selection on health for ruralurban migrants, adaptation to non-migrants' higher level of mortality after some years of urban residence due to exposure to the risk factors of non-communicable diseases and no
Strengths and limitations of this study

- Longitudinal analysis of migration and mortality at community level.

- Follow-up study combined with posterior random matching.

- Use of mobile phone interview to save on data collection costs.

- Use of bootstrap effect size to evaluate the significance of HR.

- Loss to follow-up due to non-systematic collection of mobile phone numbers.

negative selection of return-migrants to rural areas on health. ${ }^{2}$ The analysis by Lankoande and Sié suggests that in Burkina Faso, the rural-urban selection effect supersedes the urban-rural selection and adaptation effects, leading to a net urban health advantage.

In sub-Saharan African urban areas, the general health advantage may be due to selection at entry and due to another selection mechanism characterising migration processes, largely overlooked so far: negative selection at outmigration. There is increasing evidence that, when sick, poorer migrants return to their places of origin to get care. ${ }^{3-5}$ The phenomenon may be substantial in African cities where a large proportion of residents were born in rural areas; here the return of sick and poor migrants to their place of origin could result in seemingly good overall indicators of urban health. Conversely, as in Burkina Faso where migrations to urban areas are usually more permanent and often involve the whole household, sick migrants may prefer to stay in urban areas due to better access to treatment and social support in urban areas. ${ }^{2}$ The estimated contribution of migration to the general urban health advantage may depend on whether one considers morbidity or mortality. 
Table 1 Sample size for the quantitative data

\begin{tabular}{lcc}
\hline & N & $\%$ \\
\hline Migrants non-matched & 47 & 9.46 \\
Migrants matched & 450 & 90.54 \\
Total migrants & 497 & 100.00
\end{tabular}

\begin{tabular}{|lrr|}
\hline Migrants without contact number & 89 & 19.78 \\
\hline Migrants with contact number & 361 & 80.22 \\
\hline Total migrants matched & $\mathbf{4 5 0}$ & $\mathbf{1 0 0 . 0 0}$
\end{tabular}

\begin{tabular}{lrr}
$\begin{array}{l}\text { Migrants with contact number but } \\
\text { failed to contact }\end{array}$ & 116 & 32.13 \\
$\begin{array}{l}\text { Migrants successfully contacted } \\
\text { (a+b) }\end{array}$ & 245 & 67.87 \\
$\quad$ Migrants alive (a) & 215 & 59.56 \\
\hline $\begin{array}{l}\text { Migrants deceased (b) } \\
\text { Total migrants with contact } \\
\text { number }\end{array}$ & 30 & 8.31 \\
\hline
\end{tabular}

Considering the above, can we be certain that health outcomes as measured in urban populations do reflect local health risks and access to health services? Such an interrogation is the starting point of the present study, which examines the relationship between health and migration in Ouagadougou, the capital of Burkina Faso. Using Health and Demographic Surveillance System (HDSS) and data from an adult migrant follow-up survey in five informal and formal settlements in Ouagadougou, the main aim is to measure differences in health between current and former adult residents, hereafter called non-migrants and outmigrants. The objectives are to identify the health determinants of migrating out of the HDSS and to evaluate the impact of migration on health and survival after migration. Our first hypothesis is that outmigration from Ouagadougou HDSS is selective on

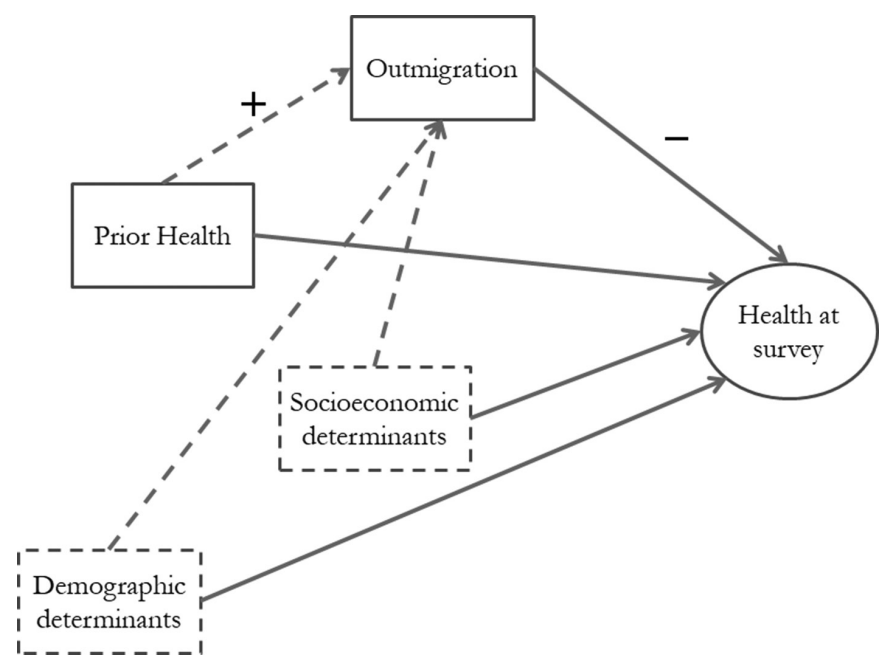

Figure 1 Conceptual model relating outmigration and health. good health (healthier people outmigrate more). The second hypothesis is that migration out of Ouagadougou negatively impacts migrants' health due to the exposure to less favourable health conditions in the destinations compared with Ouagadougou.

\section{CONTEXT AND DATA SOURCES}

Our study took place in Ouagadougou, the capital of Burkina Faso, in the Sahel region of West Africa. Its population increased from 0.7 million people in 1996 to 1.5 million in $2006,{ }^{6}$ and estimated at 1.9 million in 2012. ${ }^{7}$ Between 1996 and 2006, Ouagadougou's population growth rate was estimated at $7.6 \%$ per year. ${ }^{6} \mathrm{~A}$ breakdown of this growth showed a net migration rate of $+4 \% .{ }^{8}$ Returnees from neighbouring Côte d'Ivoire and the persistence of internal migration are the basis for this high immigration to Ouagadougou. ${ }^{8}$ For many Burkinabe youth, employment and social mobility opportunities are numerous in cities and in Ouagadougou in particular.

The study uses data collected in the Ouagadougou HDSS (also called Observatoire de Population de Ouagadougou (OPO) hereafter) set up in October 2008 by the Institut Supérieur des Sciences de la Population, University of Ouagadougou. It is located in two planned districts (Kilwin, Tanghin) and three informal settlements (Nonghin, Polesgo, Nioko II) of Ouagadougou. ${ }^{9}$

As of December 2015, the population under surveillance was estimated at 88678 residents of whom 54535 were aged 15 years or over. The backbone of the HDSS is the follow-up of the population through the registration of all demographic events (pregnancies, births, unions, migrations and deaths) and other information concerning schooling, housing, unions, employment, living standards, health, etc. This system is ideal for the identification of migrants. A migration is defined as change of residence in or out of the study area for $>6$ months. In this HDSS, the immigration rate is almost equivalent to the emigration rate, averaging 103 per 1000 persons-years over the period from 2010 to 2015 . The crude death rate is estimated at 4.3 per 1000 persons-years, and to 4.4 per 1000 among adults aged 15 years and over.

In 2010, a health survey was conducted in the HDSS area between February and June. The representative sample included 2357 adults aged 15 years and over, distributed across 1699 households. ${ }^{9}$

To assess the link between migration and health, two additional surveys were conducted. The first was a qualitative pilot study conducted in 2015 which aimed to contribute to the development of a typology of migration streams, to understand subjective perceptions of the relationship between health and migration and to prepare questionnaires for the main study. This qualitative study used a combination of focus groups and in-depth interviews, in Ouagadougou and also in Boussé, a small town located $57 \mathrm{~km}$ from Ouagadougou, and three villages surrounding Boussé, all situated in the Kourweogo 
Table 2 Determinants of migration in 2010-2014

\begin{tabular}{|c|c|c|c|c|c|}
\hline Variable & PYAR (\%) & $\begin{array}{l}\text { M1 } \\
\text { SHR (95\% Cl) }\end{array}$ & $P$ value & $\begin{array}{l}\text { M2 } \\
\text { SHR }(95 \% \mathrm{Cl})\end{array}$ & $P$ value \\
\hline \multicolumn{6}{|l|}{ Sex } \\
\hline Male & 45.64 & Ref. & & Ref. & \\
\hline Female & 54.36 & $1.549^{\star \star \star}(1.285$ to 1.869$)$ & 0.000 & $1.558^{\star \star \star}(1.287$ to 1.886$)$ & 0.000 \\
\hline \multicolumn{6}{|c|}{ Age group (years) } \\
\hline$<20$ & 11.60 & Ref. & & Ref. & \\
\hline $20-29$ & 24.47 & 1.062 (0.837 to 1.346$)$ & 0.622 & $1.050(0.826$ to 1.333$)$ & 0.691 \\
\hline 30-39 & 16.07 & 0.965 (0.699 to 1.331$)$ & 0.826 & 0.954 (0.691 to 1.316$)$ & 0.773 \\
\hline $40-49$ & 7.90 & 0.686 (0.435 to 1.082$)$ & 0.105 & 0.684 (0.429 to 1.091$)$ & 0.111 \\
\hline $50-64$ & 26.96 & $0.572^{\star \star}(0.391$ to 0.837$)$ & 0.004 & 0.655 (0.409 to 1.048$)$ & 0.078 \\
\hline $65+$ & 13.01 & 0.814 (0.502 to 1.320$)$ & 0.404 & 0.956 (0.540 to 1.694$)$ & 0.878 \\
\hline
\end{tabular}

\section{Marital status}

Never married

$22.75 \quad$ Ref.

Married

63.50

Ref.

Divorced

1.22

$0.458^{\star \star \star}$ (0.349 to 0.602$) \quad 0.000$

Ref.

Widowed

12.52

1.320 (0.610 to 2.854$) \quad 0.481$

$0.457^{\star \star *}$ ( 0.349 to 0.599$) \quad 0.000$

Education

\begin{tabular}{|c|c|c|c|c|c|}
\hline None & 56.15 & Ref. & & Ref. & \\
\hline Primary & 17.23 & 1.139 (0.901 to 1.439$)$ & 0.277 & 1.138 (0.901 to 1.438$)$ & 0.278 \\
\hline Secondary+ & 21.32 & 1.143 to (0.903 to 1.446$)$ & 0.266 & $1.147(0.907$ to 1.450$)$ & 0.254 \\
\hline Missing & 5.30 & $3.401^{\star \star}(1.562$ to 7.404$)$ & 0.002 & $3.302^{* *}(1.478$ to 7.376$)$ & 0.004 \\
\hline \multicolumn{6}{|l|}{ Occupation } \\
\hline Employer/self-employed & 31.44 & Ref. & & Ref. & \\
\hline Employee & 13.38 & $1.327^{\star}(1.015$ to 1.735$)$ & 0.038 & $1.334^{*}(1.021$ to 1.744$)$ & 0.035 \\
\hline $\begin{array}{l}\text { At school/trainee/ } \\
\text { inactive }\end{array}$ & 37.78 & $0.930(0.715$ to 1.210$)$ & 0.589 & 0.929 (0.715 to 1.208$)$ & 0.584 \\
\hline Unemployed & 12.62 & 1.262 (0.963 to 1.654$)$ & 0.091 & $1.273(0.973$ to 1.664$)$ & 0.078 \\
\hline Missing & 4.77 & 0.526 (0.223 to 1.238$)$ & 0.141 & 0.535 (0.222 to 1.288$)$ & 0.163 \\
\hline \multicolumn{6}{|l|}{ Standard living } \\
\hline Poor & 41.75 & Ref. & & Ref. & \\
\hline Middle & 47.73 & $0.886(0.739$ to 1.063$)$ & 0.193 & $0.880(0.733$ to 1.056$)$ & 0.169 \\
\hline Rich & 10.44 & $1.042(0.784$ to 1.384$)$ & 0.777 & 1.021 (0.768 to 1.359$)$ & 0.884 \\
\hline Missing & 0.09 & $0.000^{\star \star \star}(0.000$ to 0.000$)$ & 0.000 & $0.000^{\star \star *}(0.000$ to 0.000$)$ & 0.000 \\
\hline \multicolumn{6}{|l|}{ Settlement type } \\
\hline Planned & 55.77 & Ref. & & Ref. & \\
\hline Informal & 44.23 & 0.975 (0.802 to 1.185$)$ & 0.801 & 0.979 (0.806 to 1.191$)$ & 0.835 \\
\hline \multicolumn{6}{|l|}{ Hypertension } \\
\hline No & 88.80 & & & Ref. & \\
\hline Yes & 11.13 & & & 0.974 (0.675 to 1.403$)$ & 0.886 \\
\hline \multicolumn{6}{|l|}{ Obesity } \\
\hline No & 77.94 & & & Ref. & \\
\hline Yes & 22.06 & & & $1.228(0.955$ to 1.577$)$ & 0.109 \\
\hline \multicolumn{6}{|l|}{ Abdominal obesity } \\
\hline No & 86.49 & & & Ref. & \\
\hline Yes & 13.51 & & & $0.777(0.552$ to 1.093$)$ & 0.147 \\
\hline
\end{tabular}

Continued 
Table 2 Continued

\begin{tabular}{llll}
\hline Variable & PYAR (\%) & M1 & M2 \\
\hline N subjects & SHR (95\% Cl) & P value & SHR (95\% Cl) \\
N censored & 2354 & 2354 \\
N deaths & 1648 & 1648 \\
N migrations & 126 & 126 \\
\hline
\end{tabular}

Fine and Gray competing risks model with death as competing event.

Missing values (coded 99) are kept in the regression for the sake of controlling for potentially non-random missing values in some variables.

The HR for these missing values should not be interpreted.

${ }^{*} \mathrm{P}<0.05,{ }^{* *} \mathrm{p}<0.01,{ }^{* * *} \mathrm{p}<0.001$.

PYAR, person-years at risk; Ref., reference; SHR, Sub-Hazard Ratio.

province whence many Ouagadougou HDSS residents originate.

The second, quantitative, survey conducted between April and May 2016 aimed to estimate the effect of health status on migration and to assess the impact of migration on adult mortality and health. The sampling identified individuals aged 15 years and over who were interviewed during the 2010 health survey and had emigrated between 2010 and 2014. These migrants were matched with non-migrants with similar characteristics (see 'Methods' section). The health survey covered both migrants and matched non-migrants who survived through to 2016.

Seven characteristics were used for matching: sex, 5-year age group, level of education (none, primary, secondary and higher), marital status (single, married, divorced or widowed), type of neighbourhood (planned/informal), employment (inactive, unemployed, salaried, self-employed or learner) and standard of living (low, medium, high). The standard of living here is a proxy used by the OPO, and constructed on the basis of household assets. ${ }^{10}$ The method of deterministic recode linkage (using 'reclink' command of Stata) was used for matching. Only non-migrants with matching scores $>65 \%$ were selected. Of the 497 migrants identified, it was not possible to match 47 migrants $(9.46 \%)$ and the other 450 migrants were matched with non-migrants on the basis of the characteristics of the migrant at the time of migration (table 1). The analysis of the risk of a non-match (online supplementary annex 1) shows that the bias is mainly against migrants with missing data for education and occupation (who represent around $11 \%$ of migrants), as well for young female migrants below 20 (15.2\% of all migrants), and marginally against richer migrants $(12.2 \%$ of migrants) and divorced migrants (only $0.8 \%$ of migrants). The biases implies that the overall migrant mortality might be overestimated (young women and richer inhabitants presumably die less than average), although the analysis of the migration effect on mortality in the matched sample will be marginally impacted since we control for the same variables. However, we cannot exclude that the non-matched migrants may have different unobserved characteristics than the matched migrants. For the selected non-migrants, the matching score is $>90 \%$ for
$92 \%$ of non-migrants, and $57 \%$ of selected non-migrants have a matching score of $100 \%$.

After matching datasets, we obtained from relatives and neighbours a mobile phone number for each migrant. These telephone 'contact numbers' were collected between July 2015 and March 2016. Of the 450 migrants matched with non-migrants, telephone contact numbers were obtained for 361 (table 1). Interviews for both migrants and non-migrants were conducted by telephone and data recorded on tablets. In total, 245 migrants (or their relatives) out of the 361 were successfully found using phone contact numbers, of whom 30 had died (table 1). Despite high failure to contact the migrants (45.9\% of 450 matched migrants), the analysis of the risk of a non-contact (online supplementary annex 2) shows that there is no evidence of bias (none of the covariates show a significant $p$ value). Failure to contact seems therefore fairly random, although we cannot exclude that the non-contacted migrants may have different unobserved characteristics than the contacted migrants.

Death data between 2010 and 2016 were collected through the routine HDSS data collection for non-migrants and through the follow-up survey for outmigrants (ie, outmigrants who died after their migration). The 2010 and 2016 health questionnaires included aspects of both physical and mental health, the latter represented primarily by depression. The qualitative pilot study suggests that a range of other mental health conditions, including epilepsy, were associated with outmigration from Ouagadougou. First, such conditions are seen as better treated by traditional and religious healing more frequently found in rural areas, and second people with mental health problems were often sent back to the village for family care. These other aspects of mental health are not captured in the following analyses.

\section{METHODS}

Our conceptual framework is outlined in figure 1, where health is the principal outcome and outmigration the main covariate of interest. The control variables are the socioeconomic and demographic determinants. A first model will explain outmigration from OPO (relationships 
Table 3 Impact of migration in 2010-2014 on death before 2016 (Cox model)

\begin{tabular}{|c|c|c|c|c|c|}
\hline & PYAR (\%) & $\begin{array}{l}\text { M1 } \\
\text { HR (95\% Cl) }\end{array}$ & $P$ value & $\begin{array}{l}\text { M2 } \\
\text { HR (95\% Cl) }\end{array}$ & $P$ value \\
\hline \multicolumn{6}{|l|}{ Sex } \\
\hline Male & 46.55 & Ref. & & Ref. & \\
\hline Female & 53.45 & $0.606^{\star \star}(0.418$ to 0.879$)$ & 0.008 & $0.610^{\star \star}(0.420$ to 0.887$)$ & 0.010 \\
\hline \multicolumn{6}{|l|}{ Age group (years) } \\
\hline$<20$ & 10.21 & & & & \\
\hline $20-29$ & 23.28 & 1.117 (0.197 to 6.347$)$ & 0.901 & 1.166 (0.205 to 6.643$)$ & 0.863 \\
\hline 30-39 & 15.78 & 1.444 (0.215 to 9.675$)$ & 0.705 & 1.507 (0.223 to 10.17$)$ & 0.674 \\
\hline $40-49$ & 8.18 & $6.789^{*}(1.116$ to 41.29$)$ & 0.038 & $6.843^{\star}(1.108$ to 42.29$)$ & 0.038 \\
\hline $50-64$ & 28.76 & $10.58^{\star \star}(1.860$ to 60.16$)$ & 0.008 & $7.732^{*}$ (1.289 to 46.39$)$ & 0.025 \\
\hline $65+$ & 13.78 & $26.47^{\star \star \star}(4.654$ to 150.5$)$ & 0.000 & $18.51^{\star \star}(3.055$ to 112.1$)$ & 0.001 \\
\hline \multicolumn{6}{|l|}{ Marital status } \\
\hline Never married & 20.77 & & & & \\
\hline Married & 64.65 & 1.769 (0.603 to 5.194$)$ & 0.299 & 1.753 (0.593 to 5.181$)$ & 0.310 \\
\hline Divorced & 1.27 & 1.646 (0.382 to 7.094$)$ & 0.504 & 1.590 (0.367 to 6.890$)$ & 0.536 \\
\hline Widowed & 13.30 & 2.386 (0.765 to 7.444$)$ & 0.134 & 2.343 (0.747 to 7.352$)$ & 0.144 \\
\hline \multicolumn{6}{|l|}{ Education } \\
\hline None & 57.93 & & & & \\
\hline Primary & 16.64 & 1.151 (0.673 to 1.969$)$ & 0.607 & 1.182 (0.690 to 2.025$)$ & 0.542 \\
\hline Secondary+ & 21.09 & 1.435 (0.761 to 2.704$)$ & 0.264 & 1.450 (0.770 to 2.732$)$ & 0.250 \\
\hline Missing & 4.34 & 0.539 (0.129 to 2.247$)$ & 0.397 & 0.501 (0.118 to 2.124$)$ & 0.348 \\
\hline \multicolumn{6}{|l|}{ Occupation } \\
\hline Employer/freelance & 32.50 & & & & \\
\hline Employee & 13.10 & 1.074 (0.592 to 1.948$)$ & 0.814 & 1.098 (0.604 to 1.994$)$ & 0.760 \\
\hline $\begin{array}{l}\text { At school/trainee/ } \\
\text { inactive }\end{array}$ & 38.72 & 1.200 (0.715 to 2.016$)$ & 0.490 & 1.203 (0.716 to 2.022$)$ & 0.486 \\
\hline Unemployed & 11.83 & 0.552 (0.216 to 1.409$)$ & 0.214 & $0.570(0.223$ to 1.456$)$ & 0.240 \\
\hline Missing & 3.85 & 1.790 (0.282 to 11.36$)$ & 0.537 & 2.001 (0.310 to 12.93$)$ & 0.466 \\
\hline \multicolumn{6}{|l|}{ Standard living } \\
\hline Poor & 41.70 & & & & \\
\hline Middle & 47.87 & 0.712 (0.504 to 1.005$)$ & 0.054 & 0.710 (0.503 to 1.002$)$ & 0.051 \\
\hline Rich & 10.33 & 0.840 (0.467 to 1.511$)$ & 0.561 & 0.858 (0.477 to 1.543$)$ & 0.609 \\
\hline Missing & 0.10 & 0.000 (0.000 to 0.000$)$ & & 0.000 (0.000 to 0.000$)$ & \\
\hline \multicolumn{6}{|l|}{ Settlement } \\
\hline Formal & 55.41 & & & & \\
\hline Informal & 44.59 & 0.905 (0.638 to 1.283 ) & 0.574 & 0.914 (0.644 to 1.296$)$ & 0.612 \\
\hline \multicolumn{6}{|l|}{ Destination } \\
\hline No migrant & 91.73 & & & & \\
\hline Ouagadougou & 4.71 & $2.804^{\star \star \star}(1.532$ to 5.133$)$ & 0.001 & $2.757^{\star \star}(1.503$ to 5.055$)$ & 0.001 \\
\hline Out of Ouagadougou & 2.30 & $4.164^{\star \star \star}(2.156$ to 8.042$)$ & 0.000 & $4.364^{\star \star \star}(2.237$ to 8.515$)$ & 0.000 \\
\hline Missing & 1.27 & 1.676 (0.526 to 5.340$)$ & 0.383 & 1.678 (0.526 to 5.350$)$ & 0.381 \\
\hline \multicolumn{6}{|l|}{ Hypertension } \\
\hline No & 58.36 & & & & \\
\hline Yes & 7.58 & & & 1.672 (0.882 to 3.170$)$ & 0.115 \\
\hline Missing & 34.07 & & & 1.527 (0.884 to 2.639$)$ & 0.129 \\
\hline
\end{tabular}


Table 3 Continued

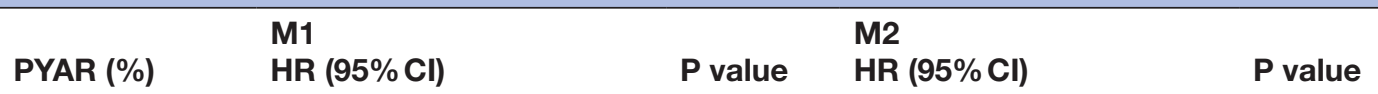

\begin{tabular}{lllll}
\hline Obesity & & & & \\
\hline No & 85.16 & & $0.730(0.308$ to 1.735$)$ & 0.477 \\
\hline Yes & 14.84 & & & \\
\hline Abdominal obesity & & & & \\
\hline No & 90.92 & & $0.845(0.318$ to 2.249) & 0.736 \\
\hline Yes & 9.08 & & 2105 & \\
N subjects & & 2105 & 11932.15 & \\
N PYAR & & 11932.15 & 181 & \\
N deaths & & 181 & & \\
\hline
\end{tabular}

Missing values are kept in the regression for the sake of controlling for potentially non-random missing values in some variables. The HR for these missing values should not be interpreted.

${ }^{\star} \mathrm{P}<0.05,{ }^{* *} \mathrm{p}<0.01,{ }^{* * *} \mathrm{p}<0.001$.

PYAR, person-years at risk; Ref., reference.

represented with dashed lines) and the second model will explain health or mortality (continuous lines). Our first hypothesis is that outmigration is selective on good health (first model). Our second hypothesis is that outmigration has a negative impact on health due to unfavourable conditions at destination (second model).

\section{Variables}

The main outcome of the first model, outmigration, is measured through migration between 2010 and 2014 out of the HDSS area by destination area (within Ouagadougou non-HDSS destinations vs out-of-Ouagadougou destinations).

The main outcome of the second model is captured for both outmigrants and non-migrants through death and composite health indices of self-declared health condition, health limitation and self-perceived health.

For both models, the main covariates are:

High body mass index ( $>25)$, abdominal obesity and hypertension (all Boolean: 1 for yes, 0 for no) as collected in the 2010 Health Survey (HS-2010). These physical health indicators could not be collected in the follow-up phone survey. The HS-2010 did not collect mental health indicators (stress) for the whole sample but, due to language skill abilities, only for those speaking either French or Moore (the Mossi language, spoken by the majority of Ouagadougou residents) and not for those speaking only other languages. Therefore, the analyses are limited to physical health indicators. Analyses on the subsample of French and Moore speakers (two-thirds of the total sample) show no effect of the stress variable in any of the models (results not shown).

Demographic indicators: sex (male, female); age group (<20, 20-29, 30-39, 40-49, 50-64, 65+ years); marital status (never married, married, divorced, widowed).
Socioeconomic indicators: education (none, primary, secondary+); standard of living (poor, middle, rich); type of settlement (planned, informal).

For all these covariates, missing values are identified by a separate indicator but are not interpreted for both models. Missing values are included to control for any association of missing value with other covariates in their effect on migration or on death. For the second model (mortality), outmigration is added as the main explanatory variable. Only the last migration (when the individual ceased to be an OPO resident) is taken into account. Outmigrants who returned to the HDSS in the 2010-2014 period are considered as 'always resident', a simplification that has little consequence since there are only 21 return migrants.

Lastly, a variant of the second model on the paired sample was limited to surviving outmigrants and their matches. This variant on health outcomes includes only the outmigration event and the 2010 physical health indicators as covariates.

\section{Statistical analyses}

To test the healthy migrant hypothesis, a competing risk mode ${ }^{11}$ was used with two categories for the dependent variable: migration out of the OPO and death in the OPO (ie, before migration). Not accounting for mortality as competing risk would bias the analysis of outmigration in relation to health status. The analysis time is the time between the 2010 survey interview date and the date of migration, death or 2016 interview.

To test the negative impact of outmigration, a Cox model is used on death with migration as the independent (timevarying) variable of interest and other variables as control variables. The date of death for outmigrants could not be reliably collected from proxy respondents but was approximated as the median date between migration and the 2016 survey date.

A variant of this second model is performed on the matched sample using traced migrants and their matches. 
Because migration is not a random event, its effect on death may be confounded by other covariates. Therefore, a matched sample is a way to control for the sociodemographic determinants of migration, and their complex interactions, in order to focus on the migration effect on death. Matches are randomly chosen on the basis of seven characteristics (as measured in 2010). Matching on known characteristics does not totally prevent mismatch on unobserved characteristics associated with both migration and health, such as genetic or behavioural dispositions, but chance that migrants and their non-migrant pairs share unobserved characteristics is higher with random matching. The applied Cox model controls for correlated variance within pairs of migrants and non-migrants (StataCorp 2017).

Lastly, this second model is tested by using health outcomes (and not death) from the data collected on outmigrants and their non-migrant matches who survived to 2016. As in the previous paired model, correlated variance within pairs is controlled for.

All effects are interpreted through HRs. An effect of migration in both models will indicate an impact of migration on death or health. After controlling for objective health status as measured in 2010, a persisting effect of migration would indicate that the impact of health is postmigration. On the contrary, a diminished effect of migration after controlling for initial health status would indicate that the health conditions prevailing before migration explain survival or health outcomes more than the migration event. Health measures are obviously endogenous to mortality (ie, a health condition might lead to death). The comparison of models with and without health variables is not actually to explain death by health but to determine whether the higher risk associated with migrant status for the whole sample is explained by premigration health conditions.

The significance of the HR will not be evaluated through $\mathrm{p}$ value but through the effect size that accounts for both $\alpha$, the risk of false positive and statistical power, that is $1-\beta$, the risk of false negative, as suggested by Halsey $e t a l^{12}$ to allow for more robust interpretation of regression results. We applied a 5\% threshold for both $\alpha$ and $\beta$. The effect size is computed a posteriori for the Cox model. We used bootstrap replication method (10000 replications) to obtain the $95 \%$ CI of the effect size for a given dependent (ie, death) risk estimate and SD of the independent variables of interest (ie, outmigration within Ouagadougou or out of Ouagadougou). For the matched sample, the replications are not done on individuals but on clusters of paired migrants and non-migrants. An HR with $p$ value $>0.05$ but situated below the $95 \%$ CI of the effect size is considered non-significant. It is considered relevant (but not conclusive) if within the $95 \% \mathrm{CI}$ of the effect size. The HR is conclusively significant if situated above the $95 \% \mathrm{CI}$ of the effect size.

\section{Patient and public involvement}

The study did not involve patients.
RESULTS

\section{Health determinants of outmigration}

Among the respondents of the HS-2010, 24.6\% (580/2354) outmigrated from the OPO between the survey in 2010 and the last 2014 round of OPO routine data collection. Among the migrants to destinations outside Ouagadougou, 25\% migrated abroad and 75\% to smaller urban centres or rural areas of Burkina Faso. Only $40 \%$ of these outmigrants returned to a previous place of residence.

The effects of non-health determinants on outmigration do not differ between the two regressions in table 2 , one without health covariates (M1) and the other with health covariates (M2). This gives credence to the assumption that health determinants do not correlate with non-health determinants. The regression with health covariates shows that none of the health indicators have an effect on outmigration.

\section{Impact of outmigration on survival}

The first regression in table 3 (M1) shows that migration status is significant and migrants who moved out of Ouagadougou have higher mortality (HR 4.16) than those moving to other Ouagadougou areas (HR 2.80). However, these HRs are within the $95 \%$ CI of the effect size (3.59-5.26 for out-of-Ouagadougou areas and 2.63-3.67 for other Ouagadougou areas, respectively, computed with bootstrap SEs). In other words, the estimated HRs are relevant but not reliably significant under the conditions of $95 \%$ statistical power, $\mathrm{p}<0.05$, and $10 \%$ correlation between migration and other covariates. In addition, the difference between the HR for the two destinations is not significant. Overall outmigration is detrimental to survival but there is not enough statistical power to conclude on the significance of this effect for either of the two destinations.

In the second regression using objective health measures as additional covariates (table 3, M2), the migrant status effect is maintained. None of the health variables are significant. The migration effect on mortality seems therefore independent of premigration health status.

With the matched sample, the regression shows (table 4, M1) a non-significant difference between non-migrants and migrants to other Ouagadougou areas but significant difference with migrants out of Ouagadougou (HR 2.63, $\mathrm{p}<0.05)$. This significance remains the same in the regression including health variables (table 4, M2). This means that the effect of migration is independent from premigration health status. Effect size computation for out-of-Ouagadougou migration shows that the estimated HR is well below 3.37, the lower range of the $95 \%$ bootstrap CI of the effect size (computed with $95 \%$ statistical power, $\mathrm{p}<0.05$, and, due to matching, no correlation between migration and other covariates). Under the same conditions, the sample would have to be at least two-thirds bigger (1365 instead of 822) to get an estimated HR of 2.63 that would satisfy both $95 \%$ statistical power and $p$ value $<0.05$. In addition, the analysis of the surviving matched sample for 
Open access

Table 4 Impact of migration in 2010-2014 on death in 2016 (Cox model, matched sample on seven variables)

\begin{tabular}{|c|c|c|c|c|c|}
\hline & PYAR (\%) & $\begin{array}{l}\text { M1 } \\
\text { HR }(95 \% \mathrm{Cl})\end{array}$ & $P$ value & $\begin{array}{l}\text { M2 } \\
\text { HR (95\% Cl) }\end{array}$ & $P$ value \\
\hline \multicolumn{6}{|l|}{ Sex } \\
\hline Male & 50.93 & Ref. & & Ref. & \\
\hline Female & 49.07 & 0.731 (0.420 to 1.273$)$ & 0.268 & 0.700 (0.386 to 1.268$)$ & 0.239 \\
\hline \multicolumn{6}{|c|}{ Age group (years) } \\
\hline$<20$ & 14.70 & Ref. & & Ref. & \\
\hline $20-29$ & 33.11 & 1.704 (0.127 to 22.85$)$ & 0.687 & 1.624 (0.120 to 21.92$)$ & 0.715 \\
\hline 30-39 & 15.09 & 2.042 (0.074 to 56.25$)$ & 0.673 & 1.804 (0.066 to 49.63$)$ & 0.727 \\
\hline $40-49$ & 5.98 & 10.183 (0.387 to 268.2$)$ & 0.164 & 8.855 (0.333 to 235.7 ) & 0.193 \\
\hline $50-64$ & 19.17 & 18.151 (0.725 to 454.4$)$ & 0.078 & 12.49 (0.453 to 344.2$)$ & 0.136 \\
\hline $65+$ & 11.95 & $37.515^{\star}(1.662$ to 846.6$)$ & 0.023 & 23.84 (0.974 to 583.4 ) & 0.052 \\
\hline
\end{tabular}

\section{Marital status}

Never married

32.02 Ref.

Married

54.96

Ref.

Divorced

1.13

1.675 (0.291 to 9.634$)$

Ref.

Widowed

11.89

0.695 (0.039 to 12.24$)$

0.564

\section{Education}

\begin{tabular}{|c|c|c|c|c|c|}
\hline None & 54.79 & Ref. & & Ref. & \\
\hline Primary & 16.16 & 1.366 (0.623 to 2.996$)$ & 0.437 & 1.416 (0.616 to 3.254$)$ & 0.412 \\
\hline Secondary+ & 23.55 & 0.943 (0.166 to 5.357$)$ & 0.947 & 0.918 (0.165 to 5.103$)$ & 0.922 \\
\hline Missing & 5.50 & 0.310 (0.086 to 1.117$)$ & 0.073 & 0.309 (0.079 to 1.210$)$ & 0.092 \\
\hline Occupation & & 1.011 (0.510 to 2.004$)$ & 0.974 & 1.052 (0.519 to 2.132 ) & 0.888 \\
\hline Employer/freelance & 30.14 & 0.480 (0.138 to 1.669$)$ & 0.248 & 0.506 (0.150 to 1.711$)$ & 0.273 \\
\hline Employee & 12.96 & 1.184 (0.491 to 2.857 ) & 0.707 & 1.251 (0.513 to 3.047$)$ & 0.623 \\
\hline $\begin{array}{l}\text { At school/trainee/ } \\
\text { inactive }\end{array}$ & 39.43 & & & & \\
\hline Unemployed & 12.60 & Ref. & & Ref. & \\
\hline Missing & 4.87 & 3.388 (0.553 to 20.76$)$ & 0.187 & 3.348 (0.489 to 22.95$)$ & 0.218 \\
\hline \multicolumn{6}{|l|}{ Standard living } \\
\hline Poor & 47.26 & Ref. & & Ref. & \\
\hline Middle & 43.39 & 0.993 (0.627 to 1.573$)$ & 0.977 & 0.977 (0.601 to 1.589$)$ & 0.926 \\
\hline Rich & 9.23 & 0.912 (0.335 to 2.484$)$ & 0.857 & 0.921 (0.327 to 2.593) & 0.877 \\
\hline Missing & 0.12 & 0.000 (0.000 to 0.000$)$ & 0.000 & 0.000 (0.000 to 0.000$)$ & 0.000 \\
\hline \multicolumn{6}{|l|}{ Settlement } \\
\hline Formal & 45.72 & Ref. & & Ref. & \\
\hline Informal & 54.28 & 0.716 (0.469 to 1.094$)$ & 0.123 & 0.745 (0.485 to 1.144$)$ & 0.178 \\
\hline \multicolumn{6}{|l|}{ Destination } \\
\hline Non-migrant & 77.65 & Ref. & & Ref. & \\
\hline Ouagadougou & 12.82 & 1.724 (0.953 to 3.119$)$ & 0.072 & 1.728 (0.942 to 3.171$)$ & 0.077 \\
\hline Out of Ouagadougou & 6.31 & $2.630^{*}(1.234$ to 5.609$)$ & 0.012 & $2.712^{*}(1.200$ to 6.130$)$ & 0.016 \\
\hline Missing & 3.23 & 1.232 (0.385 to 3.942$)$ & 0.725 & 1.242 (0.389 to 3.968$)$ & 0.715 \\
\hline \multicolumn{6}{|l|}{ Hypertension } \\
\hline No & 69.28 & & & Ref. & \\
\hline Yes & 6.36 & & & 1.812 (0.679 to 4.834$)$ & 0.235 \\
\hline Missing & 24.37 & & & 1.810 (0.734 to 4.464$)$ & 0.197 \\
\hline
\end{tabular}


Table 4 Continued

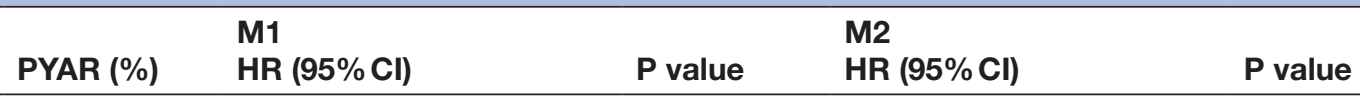

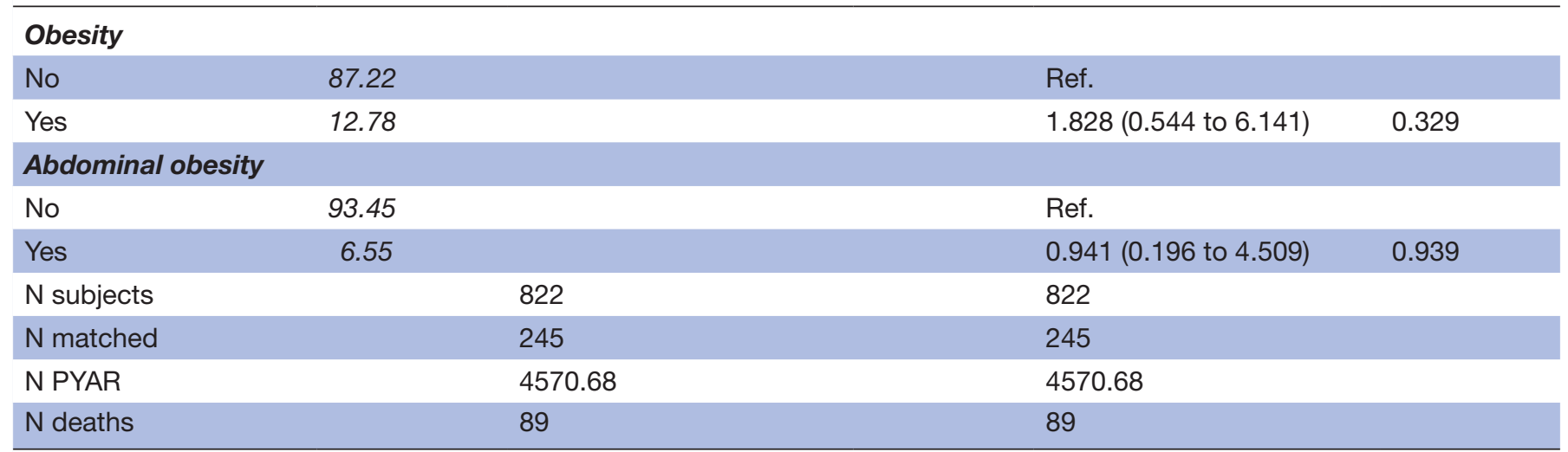

In both models, SEs are corrected for matched clusters. The seven variables used for matching are: sex, age group, level of education, marital status, type of neighbourhood, employment and standard of living. Missing values are kept in the regression for the sake of controlling for potentially non-random missing values in some variables. The HR for these missing values should not be interpreted.

${ }^{*} \mathrm{P}<0.05,{ }^{* *} \mathrm{p}<0.01,{ }^{* * *} \mathrm{p}<0.001$.

PYAR, person-years at risk; Ref., reference.

whom 2016 health status could be collected showed that none of the migration and health variables explain survivors' health status in 2016 (results not shown).

\section{DISCUSSION}

Our analytic results are so-called negative results, that is, they did not confirm our main hypothesis. We conclude through various methods (non-matched and matched samples, death or health outcomes) that there is not enough evidence that migration, in or out of Ouagadougou, led to higher mortality or worse health. It is worth noting that even if there was enough evidence to confirm our hypothesis, the higher mortality associated with outmigration would affect a relatively small part of the population. In a 4-year period, $<8 \%$ of adults migrated out of Ouagadougou while 16\% headed to other Ouagadougou destinations. The impact on underestimation of health risks in the HDSS would be negligible, even with a high impact of bad health on outmigration.

This project made use of both a health survey conducted in 2010 and of the HDSS framework to monitor deaths and outmigration between 2010 and 2016. In addition, matching was used to save substantially on follow-up costs and to control covariate interactions for counterfactual analysis. This methodology could potentially be extended in most HDSS frameworks, where surveys are conducted on a regular basis on samples.

However, it should be noted that loss to follow-up should not be underestimated, even when the constraints of face-to-face interviews are lessened by mobile phone interviews. Only $54 \%$ of the migrants could eventually be reached through mobile phone $(245 / 450)$. No significant difference was found between reached and non-reached migrants on the basis of observed characteristics. However, unobserved characteristics associated with loss to follow-up may have generated a bias generated in the analysis of the migration-mortality relationship. In addition, no objective health measures could be gathered from migrants using phone interviews.

Based on these results, methodological advice for future research is to collect mobile phone numbers more systematically to make phone interview a viable alternative to prospective face-to-face interview, for both the treated and non-treated (eg, non-migrants and outmigrants after their departure). In our case, half of the lostto-follow-up migrants could not be reached because of lack of phone contacts. This could have been reduced if we had collected phone numbers in 2010 and maintained a phone number database throughout the 2010-2015 period. Mobile phone interviews can be conducted more systematically. Most questions can be asked at a distance (especially to make routine corrections of data collection errors), while face-to-face interviews should be kept to the absolute minimum to avoid respondent fatigue and failure to meet the respondent. The proportion of respondents who refused to respond on the phone was quite low $(<10 \%)$.

HDSS platforms can be used to analyse the long-term impact of health through sample follow-up, but need to use large samples. Although the HS-2010 gathered data on $>2350$ adults, it was not big enough considering the low prevalence of events at stake $(<20 \%)$ and the loss to follow-up (around 50\%). With similar figures, the sample needed to get enough statistical power should have been at least doubled to 5000 adults.

We also advise using posterior matching (ie, matching of non-treated after identification of the treated) whenever possible. Randomisation is difficult if not impossible to achieve in social sciences in general, and migration analysis in particular, and matching is a good alternative 
to randomisation for counterfactual analysis with longitudinal data. Random matching does not completely prevent mismatch on unobserved characteristics associated with both migration and health, but it certainly reduces the risk of misinterpretation due to differences in characteristics between treated and non-treated. We finally also advise the use of the effect size (and its 95\% $\mathrm{CI})$ rather than the $\mathrm{p}$ value to evaluate the significance of the estimated HR accounting for the sample's statistical power.

\section{CONCLUSION}

The study neither confirms the hypothesis that outmigration is selective on health nor confirms the hypothesis that migration away from Ouagadougou has a negative effect on mortality or other health outcomes. Indeed, there is no evidence of a negative effect of migration on health for survivors, and the higher mortality of outmigrants after their migration away from Ouagadougou is not supported after proper control for confounders through matching and consideration of effect size.

Therefore, measures of health and mortality in the $\mathrm{OPO}$ are marginally biased by migration and are therefore generalisable to similar areas in Ouagadougou. It is not worth extending the follow-up study on a larger sample of outmigrants to control for potential outmigration effect. As for our initial question, we can provisionally say that health outcomes as measured in the Ouagadougou population do reflect local health risks and access to health services despite high migration intensity.

Acknowledgements The authors acknowledge institutional support from the Institut Supérieur des Sciences de la Population, Université de Ouagadougou IJoseph-Ki-Zerbo (Ouagadougou, Burkina Faso) and the Centre de Recherche en Démographie et Sociétés, Université Catholique de Louvain (Louvain-la-Neuve, Belgium). The authors would like to thank Michael J White, Mark A Collinson, Carren Ginsburg, Bruno Lankoandé and Bruno Masquelier for their helpful friendly reviews of an earlier version of this paper. The authors are responsible for all remaining errors

Contributors PNLB provided team co-leadership, conceptualised the methods, wrote the first draft and reviewed the manuscript. ABS provided team coleadership, headed the fieldwork, contributed to the writing of the article and reviewed the manuscript. SS supervised the fieldwork, cleaned the databases, implemented the exploratory and regression analyses. SR conducted the qualitative survey, contributed to the quantitative questionnaire design, suggested interpretations of the results and reviewed the manuscript. All authors approved the final submission.

Funding The project 'Moving targets: identifying health risks in mobile populations through longitudinal follow-up of formal and informal settlements in Ouagadougou' has received funding from the PII-2015 scheme (Projets d'Initiative Innovante: secteur 130-Politique en matière de population/santé et fertilité; Sous-secteur: 13010-Population policy and administrative management) of the Académie de Recherche et d'Enseignement supérieur (ARES) of Belgium. International travels and meetings were funded by DEMOgraphy-STatistics-for-Africa (DEMOSTAF) project under the umbrella of H2020-MSCA-RISE-2015 (project number 690984).

Competing interests None declared.

Patient consent for publication Not required.

Ethics approval The ethical aspects of the Moving Targets project have been approved by the Comité national pour la recherche en santé, Ministère de la santé of Burkina Faso (2015-6-082).

Provenance and peer review Not commissioned; externally peer reviewed.

Data sharing statement Anonymised data and Stata statistical analysis programs are available on request from the corresponding author (ORCID Id: 0000-00026278-0597) at any time after publication of this manuscript and can be reused on condition that this manuscript is cited.

Open access This is an open access article distributed in accordance with the Creative Commons Attribution Non Commercial (CC BY-NC 4.0) license, which permits others to distribute, remix, adapt, build upon this work non-commercially, and license their derivative works on different terms, provided the original work is properly cited, appropriate credit is given, any changes made indicated, and the use is non-commercial. See: http://creativecommons.org/licenses/by-nc/4.0/.

\section{REFERENCES}

1. Urquia ML, Gagnon AJ. Glossary: migration and health. J Epidemiol Community Health 2011;65:467-72.

2. Lankoande B, Sié A. Selective adult migration and urban-rural mortality differentials in Burkina Faso. Population 2017;72:197-218.

3. Clark SJ, Collinson MA, Kahn K, et al. Returning home to die: Circular labour migration and mortality in South Africa. Scand $J$ Public Health Suppl 2007;69:35-44.

4. Bocquier P, Collinson MA, Clark SJ, et al. Ubiquitous burden: the contribution of migration to AIDS and Tuberculosis mortality in rural South Africa. Etude Popul Afr 2014;28:691-701.

5. Collinson MA, White MJ, Bocquier P, et al. Migration and the epidemiological transition: insights from the Agincourt sub-district of northeast South Africa. Glob Health Action 2014;7:23514-5.

6. INSD. Recensement Général de la Population et de l'Habitation de 2006. Résultats définitifs. Ouagadougou: Institut national de la statistique et de la démographie, 2008:52.

7. INSD. Ouagadougou. Énumération de la Population de Ouagadougou et Bobo Dioulasso (EPOB) de 2012) Ouagadougou: Institut national de la statistique et de la démographie, 2018.

8. Guengant J-P. Evolution passée et future de la ville de Ouagadougou. In: Boyer F, Delaunay D, eds. Peuplement de Ouagadougou et développement urbain: rapport provisoire. Paris: Institut de recherche pour le développement, Université Paris I, 2009:42-9.

9. Rossier C, Soura AB, Duthé G, et al. Non-communicable disease mortality and risk factors in formal and informal neighborhoods, ouagadougou, burkina faso: Evidence from a health and demographic surveillance system. PLoS One 2014;9:e113780.

10. Soura A, Pison G, Senderowicz L, et al. Religious differences in child vaccination rates in urban Africa: Comparison of population surveillance data from Ouagadougou, Burkina Faso. African Population Studies 2013;27:174.

11. Fine JP, Gray RJ. A proportional hazards model for the subdistribution of a competing risk. J Am Stat Assoc 1999;94:496-509.

12. Halsey LG, Curran-Everett $D$, Vowler SL, et al. The fickle $P$ value generates irreproducible results. Nat Methods 2015;12:179-85. 